\title{
Issues of building an intelligent water transport management system
}

\author{
Artem Butsanets ${ }^{1 *}$,Evgeniy Ol’Khovik ${ }^{1}$, Vladimir Karetnikov ${ }^{1}$, Victor Senchenko ${ }^{2}$ \\ ${ }^{1}$ Admiral Makarov State University of Maritime and Inland Shipping, 5/7, Dvinskaya st., St. Petersburg, 198035 , \\ Russia \\ ${ }^{2}$ Admiral Ushakov State Maritime University, 93, Lenin's avenue, Novorossiysk, 353918, Russia
}

\begin{abstract}
The current level of technology in terms of instruments, devices and software enables the construction of local intelligent transport systems that contribute to the prevention of accidents. It has become possible to build crewless and unmanned vessels. Geographical information services such as Google Maps, Mapbox, OpenStreetMap have already shown their effectiveness. The relevance of the study stems from the possibility to partially automate ship's route planning nowadays. As navigation monitoring is carried out by means of VHF (very high frequency) - Automatic Identification System (AIS) receivers, the authors propose to collect and analyse data. However, for the construction of the geographical information system and data processing, the authors justified the proposal to build the concept, methodological foundations, mathematical models and scenarios, which will serve as the basis for the development of software for the geographical information system. They propose data types for constructing time/speed matrices for planning optimal routes based on the current navigational situation. The data collected will provide a 12-36 hour forecast and allow for the determination of vessel speeds and times, considering vessel specifications, traffic of other vessels, queue at locks, forecast of hydro- and meteorological conditions, estimates of traffic intensity and density. The service is expected to optimise the route in terms of speed and journey time to meet the transport and logistics challenge.
\end{abstract}

\section{Introduction}

Inland waterways have a high volume of freight and passenger traffic. The limited capacity of rivers and canals is due to many navigational hazards (complex bottom topography, shallow depths, shallow rivers, heterogeneous currents) and the variability of hydrometeorological and hydrological conditions. Continuous improvement of geographical information services such as Google Maps, MapBpx, OpenStreetMap, etc. already allows high accuracy in constructing optimal routes for road transport, with respect to traffic intensity and density, forecasting average traffic speed, travel time, etc. [1,2]

In parallel, modern advances in science and technology allow the construction of highly automated vessels. They reduce or eliminate the role of the ship's crew and enable the implementation of remotecontrolled or autonomous modes of operation [3-5]. This requires the building of a concept, methodological foundations, mathematical models and scenarios that will serve as the foundation for the development of the geographical information system software. This approach will correctly predict the ship's route and control its timing, considering natural and industrial factors.
In addition, traditionally the task of route planning has relied heavily on the expertise of the captain and his crew. At the same time, statistics show that about half of accidents on inland waterways are caused by crew mistakes. Shipping analyses are increasingly becoming the priority to prevent accidents on busy waterways and keep the number of accidents on the water to a minimum. Information security has also received much attention [6-7]. The relevance of this study is due to the possibility of partial automation of ship route planning already nowadays. [8-9] It is possible to monitor shipping using VHF receivers of automatic identification system (AIS) with the subsequent data processing which will allow understanding better of the mechanism of emergencies on the congested waterways.

The complex task of creating a system for geographical information services, which allows planning of vessel routes in an automated mode and further monitoring and control of remotely-controlled or autonomous vessels requires the creation of geographical services for water transport, which allows forecasting travel time, creating recommended routes based on vessel specifications, currents, guaranteed depths, route congestion and ports on the constructed route.

\footnotetext{
*Corresponding author: butsanetsaa@gumrf.ru
} 


\section{Methods and materials}

One of the main scientific problems is the lack of a methodological framework and mathematical multidimensional models describing the operation of water transport and allowing the creation of scenarios working with software components for geographical information services. Such services allow for automated calculation of ship times, selection of the best route and driving speed.

Building such a mathematical model requires first constructing the concept of integrated spatial information processing system and developing a methodological framework to correctly correlate ship specifications (size, draft, etc.) and external factors such as guaranteed depths, route and port congestion and speed of currents. Such methodological frameworks should be the foundation for the construction of multidimensional model building methods.

There are currently no shipping traffic data (track congestion, mooring times, routes) available in the public domain, and the project plans to have this data processed and published in leading scientific journals. In addition, the AIS will be used to derive values that will allow the construction of multivariate data models [1012] on navigation on the Neva River during navigation and comprehensive analysis of the data obtained. AIS is a multifunctional information and technical system, the equipment of which is installed on ships in the class and in coastal services in order to automate the exchange of navigation information and ensure the safety of navigation. Such systems are installed both on sea and river vessels, as well as on vessels of mixed "river-sea" navigation.

AIS allows you to:

1. Ensure the automatic and regular transmission of information to ships and coastal services, including information about the vessel, coordinates, course, speed and other data;

2. Provide automatic reception, processing and display of static, dynamic and flight information, as well as service information from other vessels and coastal services;

3. Implement automatic tracking (routing of traffic) of vessels equipped with AIS, in order to prevent collisions, as well as control and regulation of navigation;

4. Implement an automated exchange of messages related to the safety of navigation between ships and coastal services.

The principle of operation of the AIS is explained in Figure 1. Vessels equipped with AIS transponders, while on the high seas, in coastal areas or on the Inland waterways, regularly transmit standard messages in the VHF range of the maritime mobile radio service containing information about the vessel, its coordinates, course, speed vector, dangerous cargo on board, port of destination, time of arrival and others. At the same time, each vessel equipped with an AIS transponder receives similar information from vessels located within a range limited by the propagation of VHF radio waves $(20-30$ miles). The received information is automatically processed and displayed on one of the ship's navigation displays. In addition, AIS messages can be received by special receivers, the cost and weight and size indicators of which are significantly less than transponders. Such receivers are very often used in coastal systems for monitoring and controlling the movement of ships, where it is not necessary to transmit data to ships. Synchronization of the operation of all AIS transponders (ship and shore) is provided by the global navigation satellite system (GNSS) GLONASS / GPS, which is also a source of transmitted dynamic information.

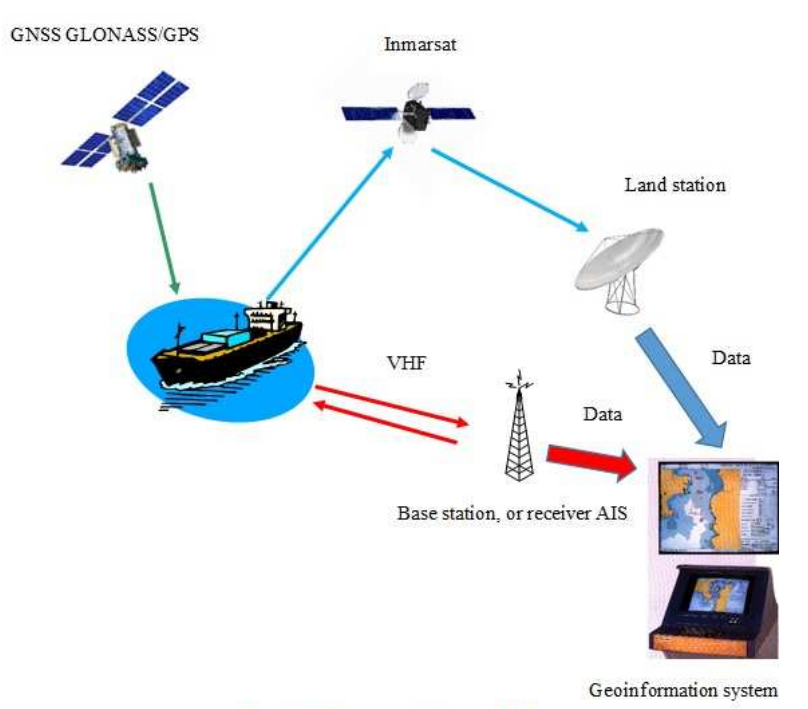

Figure 1. The AIS principle of operation.

In coastal areas where AIS base stations or receivers are installed, information transmitted by ships is received by base stations or receivers and is made available to coastal services and systems. In addition, with a significant distance of ships from the shore, AIS messages can be received by some satellite communication systems. Further to the earth station, this data can also be sent to the coastal service or the system. Usually, in order to obtain a complete picture of navigation in the controlled area, the AIS base stations or receivers are combined into networks that allow integrating information from individual base stations or receivers with each other. In coastal areas, the accuracy of determining the coordinates of ships using GNSS and, consequently, the efficiency of AIS can be improved by means of coastal reference stations and radio beacons transmitting differential corrections for ships.

The AIS base (shore) stations can operate in an active mode, controlling the operating mode of ship stations and transmitting to them information related to the safety of navigation (local navigation warnings, differential corrections for GNSS, data on ships accompanied by VTS, and others). 
When ships are located outside the areas of operation of coastal base stations and in the open sea, the AIS can operate in the long-distance communication mode, including through the Inmarsat satellite communication system. In this mode, information is automatically transmitted from ships to coastal services and systems for the purpose of monitoring navigation.Thus, the scenarios developed will be built based on actual shipping conditions.

There is also a need for the development of calculation methodology for justification of location of
AIS VHF receiver network for seamless coverage and monitoring of navigation on the studied section of the Neva River, their installation, arrangement of data recording. It is also necessary for the development of methods to describe, store, integrate and process heterogeneous information (spatial and navigational) for its storage in the database and further processing as part of a unified information system, considering the information received from VHF AIS receivers installed on the Neva River water area.

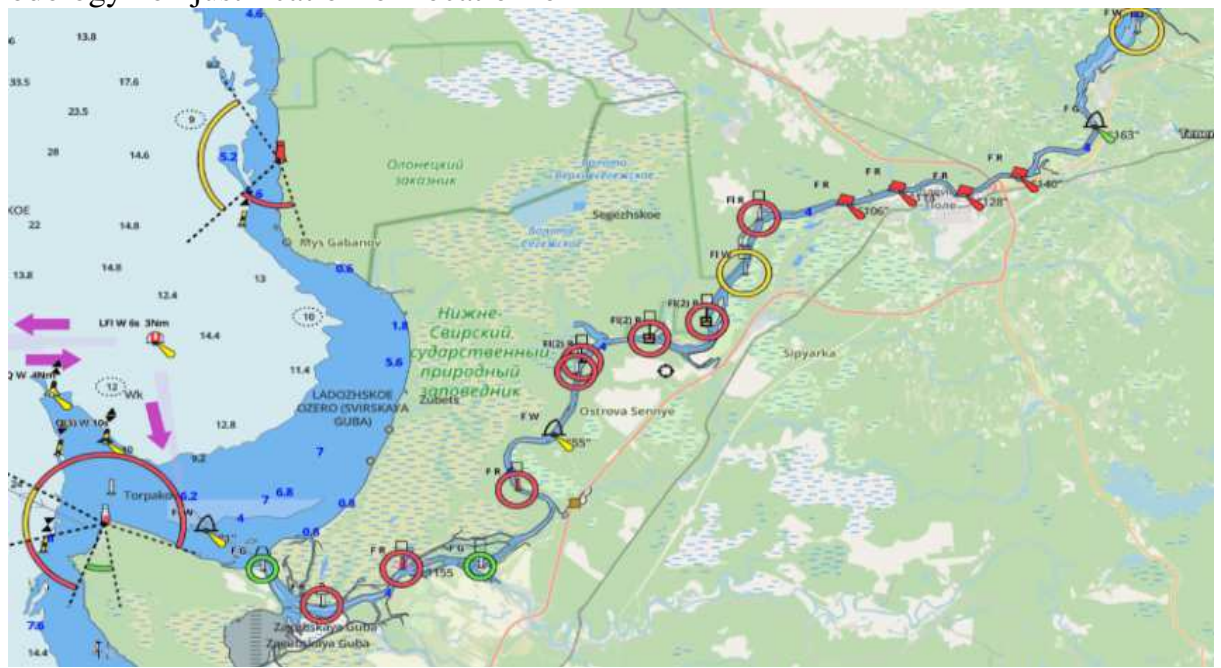

Figure 2. Electronic navigation map.

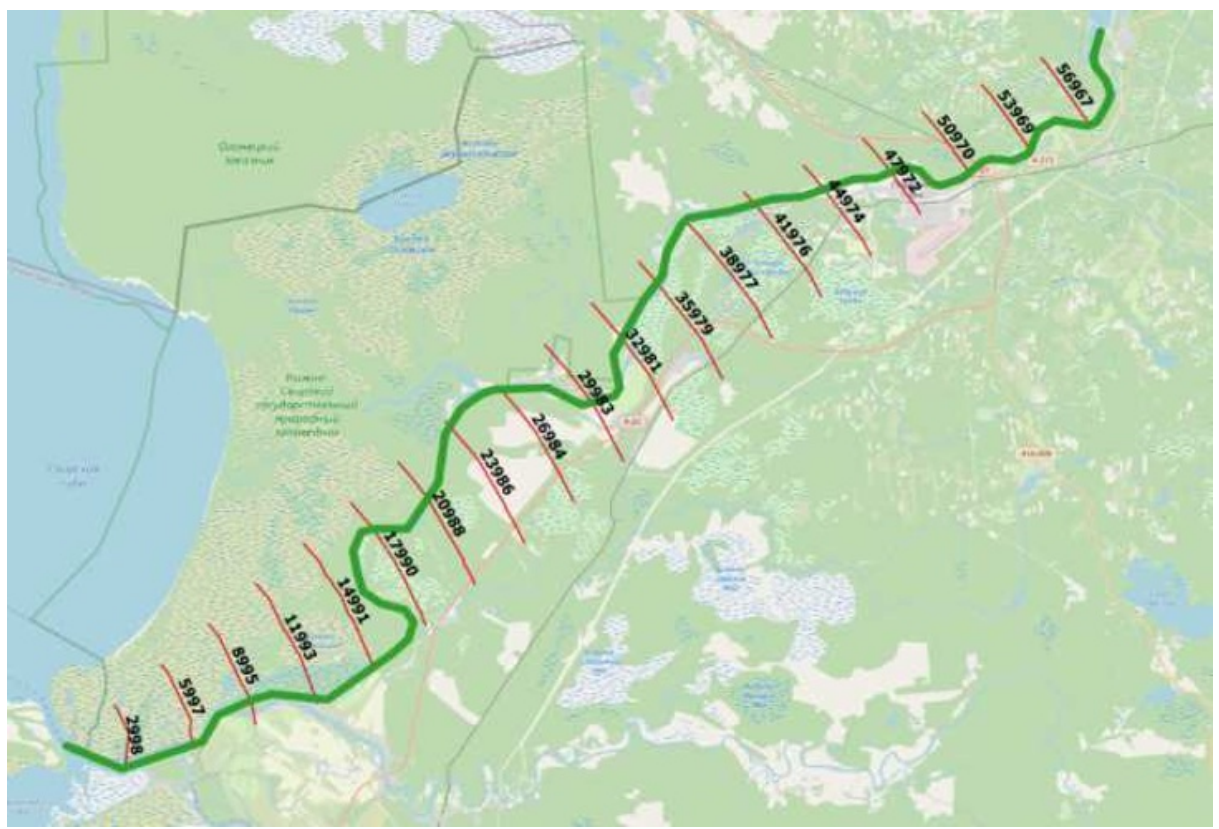

Figure 3. Geocoding of the waterway section

\section{Results}

The AIS provides baseline data on navigation on the Neva River during the navigation period and allows for a comprehensive analysis of the data. It is currently not possible to obtain open data on shipping (e.g. track congestion, mooring times, routes). Modern electronic navigation charts are used for navigation but not for transport and logistics tasks (Figure 1). It is possible to collect such data by installing VHF AIS receivers with seamless coverage. The next step is to divide the waterway (Figure 2, Figure 3) into straight sections. This will allow the collection of time and/or speed information at a given location. Installing additional equipment (or connecting to existing equipment) will collect weather data. Thus it is possible to construct a matrix of speeds and/or times for the whole route, since the distance is known in advance (Figure 2). 
The data set can include the ship's speed, draught, local weather conditions, ship specifications and other data.

Machine learning algorithms can help to build multivariate models based on k-means (clustering), support vector methods (linear regression); and logistic regression.

The data provided can be further used to refine the time/speed matrices for planning optimal routes based on the current navigational situation. Figure 3 shows an example of such a matrix. The corrected time/speed matrix is converted into a set of equal integral gradient lines (isolines) along the entire length of the route, based on online monitoring, it is continuously recalculated to reflect the current navigational situation.

The data collected will make it possible to make a forecast for 12-36 hours and determine vessel speed and time, considering vessel specifications, traffic of other vessels, queue at locks, forecast of hydro- and meteorological conditions, traffic intensity and density estimates. To solve the transport and logistics task, the service can offer route optimisation options in terms of speed and journey time. Correction of the time/speed matrix with regard to constraints and machine learning results.

\begin{tabular}{|l|l|l|l|l|l|l|l|l|l|l|l|}
\hline ID & Longitude & Lattitude & 1 & 2 & 3 & 4 & 5 & 6 & 7 & 8 & 9 \\
\hline 1 & 32.820621 & 60.48716 & - & 2848.3 & 6407.5 & 7291.1 & 8980 & 10020.5 & 12489.2 & 15989.8 & 16933.9 \\
\hline 2 & 32.868084 & 60.47692 & 2848.3 & - & 4024.2 & 5247.2 & 6970.8 & 7991.6 & 10260.3 & 13938.9 & 14935.4 \\
\hline 3 & 32.937118 & 60.488915 & 6407.5 & 4024.2 & - & 1510.4 & 3084.3 & 4051.2 & 6236.1 & 9934.5 & 10942.8 \\
\hline 4 & 32.950357 & 60.500794 & 7291.1 & 5247.2 & 1510.4 & - & 1728.3 & 2762.4 & 5203.7 & 8741.8 & 9717.9 \\
\hline 5 & 32.978728 & 60.50749 & 8980 & 6970.8 & 3084.3 & 1728.3 & - & 1041.3 & 3587.6 & 7022.3 & 7992 \\
\hline 6 & 32.996856 & 60.510219 & 10020.5 & 7991.6 & 4051.2 & 2762.4 & 1041.3 & - & 2606.9 & 5981.8 & 6955.7 \\
\hline 7 & 33.044024 & 60.507674 & 12489.2 & 10260.3 & 6236.1 & 5203.7 & 3587.6 & 2606.9 & - & 3804.2 & 4850.8 \\
\hline 8 & 33.099571 & 60.528069 & 15989.8 & 13938.9 & 9934.5 & 8741.8 & 7022.3 & 5981.8 & 3804.2 & - & 1052.5 \\
\hline 9 & 33.11348 & 60.534569 & 16933.9 & 14935.4 & 10942.8 & 9717.9 & 7992 & 6955.7 & 4850.8 & 1052.5 & - \\
\hline $\mathrm{N}$ & $\ldots \ldots$ & $\ldots \ldots$ & $\ldots \ldots$ & $\ldots \ldots$ & $\ldots \ldots$ & $\ldots \ldots$ & $\ldots \ldots$ & $\ldots \ldots$ & $\ldots \ldots$ & $\ldots \ldots$ & $\ldots \ldots$ \\
\hline
\end{tabular}

Figure 4. Passage time matrix, in seconds.

\section{Discussion}

Based on the data collected, it is possible to synthesise multi-dimensional shipping data models [10-12] for geographical information systems. This will allow the development of an information object interaction methodology for the logical description of spatial information and multidimensional shipping data models, then methods to describe, store, integrate and process heterogeneous information (spatial and shipping). It is also necessary to develop an organisational structure for the efficient distribution, storage and processing of information. The research will analyse the types of software implementation of the proposed methods to describe, store, integrate and process information (including by means of machine learning technologies) as part of geographical information systems and develop an assessment of the effectiveness of the proposed system.

\section{Conclusion}

Thus, after solving the problems described in this paper and implementing them, it will be possible to construct recommended routes and display travel times according to the possible speed of the specific vessel. Such services will allow crews of large vessels to pre-select speeds in certain sections of the water area, based on the experience of previous vessels, as well as the congestion of each section. This can reduce fuel consumption, travel time [13-14]. In the future, with the introduction of remotely piloted or autonomous vessels on inland waterways, project results will enable safe and efficient control of such vessels, tracking their movements and choosing the most rational routes and speeds, considering external factors (e.g. wind direction and speed, direction and speed of currents, guaranteed depths). Obviously, it is important to consider the solutions suggested in the paper [15].

\section{References}

1. J. Li, X. Pei, , X. Wang, D. Yao, Y. Zhang, Y. Yue, Tsinghua Science and Technology, 26(4), 403-416, (2021) DOI: 10.26599/TST.2020.9010014

2. H. Gong et al. Computers, Environment and Urban Systems, 36 (2), 131-139, (2012) DOI: 10.1016/j.compenvurbsys.2011.05.003

3. A. Ivanova, A. Butsanets, V. Breskich, T. Zhilkina, Autonomous Shipping Means: The Main Areas of Patenting Research and Development Results, 54, (2021). doi:10.1016/j.trpro.2021.02.132.

4. V. Karetnikov, et al., AISC 1258, (2021). doi:10.1007/978-3-030-57450-5_36.

5. I. Shipunov, A. Nyrkov, V. Korotkov, O. Alimov, T. Knysh, E3S Web of Conferences. 203, 05005, (2020) DOI: 10.1051/e3sconf/202020305005 
6. S. Sokolov, A. Nyrkov, T. Knysh, A. Shvets, Proceedings of the XIII International Scientific Conference on Architecture and Construction 2020, Springer, Singapore, 84-100, (2021) DOI: 10.1007/978-981-33-6208-6_9

7. T. Hogg, S. Ghosh, Australian Journal of Maritime \& Ocean Affairs, 8 (3), 206-222. (2016) 10.1080/18366503.2016.1229244

8. V. Karetnikov, E. Ol'khovik, A. Butsanets, A. Ivanova, Proceedings of the XIII International Scientific Conference on Architecture and Construction 2020, Springer, Singapore, 40-46, (2021). doi:10.1007/978-981-33-6208-6_5.

9. A. Heßelbarth et al. IEEE Intelligent Transportation Systems Magazine,12(3), 123-135, (2020) DOI: 10.1109/MITS.2020.2994103

10. A. Cuzzocrea, 32nd International Conference on Scientific and Statistical Database Management, 1-6, (2020). DOI: 10.1145/3400903.3409117

11. A. Gosain, J. Singh, IET Software. 14(3), 275282, (2020). DOI: 10.1049/iet-sen.2019.0150

12. A. V. Kalach et al. IOP Conference Series: Materials Science and Engineering, 862(5), 052002, (2020) DOI: $10.1088 / 1757-$ 899X/862/5/052002

13. Y. Yin, J. S. L. Lam, N. K. Tran, International Journal of Shipping and Transport Logistics, 13 (1-2), 156-184 (2021). DOI: 10.1504/IJSTL.2021.112922

14. D. V. Dmitrienko, A. A. Chertkov, S. V. Saburov, Vestnik Gosudarstvennogo universiteta morskogo I rechnogo flota imeni admirala $S$. O. Makarova 9.2, 422-431, (2017). DOI: 10.21821/2309-51802017-9-2-422-431.

15. M. Rodger, R. Guida Remote Sensing, 13(1), 104, (2021) DOI: 10.3390/rs13010104 